\title{
A digital inclusion
}

\section{Empowering all Australians}

\author{
Peter Walton \\ Infoxchange \\ Tegan Kop \\ Infoxchange \\ David Spriggs \\ Infoxchange \\ Brendan Fitzgerald \\ Infoxchange
}

Summary. Digital technologies now pervade every aspect of modern Australian society. Almost every aspect of how we live, work and play - from getting an education, accessing health care, communicating with friends to getting a job - is influenced by digital technology. In this era of rapid change, the trajectory of economic development, our future prosperity and our ambitions to be a socially inclusive nation will all be influenced by the increasing growth and reliance on digital technologies as a part of everyday life. Digital inclusion (and equality) is increasingly becoming one of the major social justice challenges of our time. Digital inclusion is vital to employment participation, economic development, educational achievement, social and civic inclusion, health and wellbeing.

Many people continue to be digitally excluded in Australia and, importantly, as technology changes there is a growing risk of a participation gap in terms of a person's ability to engage with technology. At present, the response to such a major issue in Australia is fragmented and only occasionally addressed holistically. Comprehensive national research on this issue is limited, the longer-term costs of digital exclusion have not been fully explored, nor do we have a national plan to mobilise a whole of community effort that ensures that all Australians have the skills and opportunity to benefit from digital citizenship.

The purpose of this paper is to explore the current needs, challenges and benefits of digital inclusion in Australia. It explores how the concept of inclusion is evolving with changes in technology and to social structures. This article is a précis of a White Paper commissioned by Telstra. The aim is to advance our understanding of digital inclusion and introduce a more refined conceptual framework for defining and addressing digital equality. 


\section{Introduction and Background}

In 2013 the world has become a fundamentally digitally mediated place. Here in Australia, like other parts of the developed and developing world, technology has become irrevocably embedded in the very fabric of society. For many people life without a mobile phone or access to the Internet is unthinkable and perhaps unimaginable. It is true that a range of Australian government policies and programmes have attempted to address inequalities in ICT access and use since the late 1990s. However despite these attempts, key determinants of Internet access and use such as age, income, educational attainment and Indigenous status are proving to be persistent. At the same time more complicated and nuanced factors are likely to be determining the way people use the Internet (Notley 2008). This paper attempts to develop a holistic framework for and assess the value of a digital equality policy framework.

Technology now affects almost every dimension of how we live, work and play. In a relatively short space of time we have seen the rapid, wholesale digitisation of our communication practices so much so that 'digital inclusion' materially affects the cultural, social and economic well-being of all Australians. We have effectively moved from justifying what goes online, to justifying what does not. In many ways being connected - being digitally included - is ceasing to be an 'opt-in' or 'opt-out' choice if one wants to avoid disadvantage (Walton 2013). There is simply more to lose from digital exclusion than there has been before.

Access to the Internet is fast becoming seen as a basic utility not dissimilar to gas, electricity or water and whilst this concept may seem like a stretch to some, being deprived of any basic utility creates considerable hardship and not having access to the digital world is being seen in this light.

In early 2010, a poll conducted for the BBC World Service found that almost four in five people around the world believed that access to the Internet is now a fundamental right (BBC News 2010).

France has ruled that access to the Internet is a basic human right (Sparks 2009) and in 2010 Finland became the first country in the world to make access to broadband a legal right for every citizen, with policy ambitions to ensure minimum download speeds of 10oMbps by 2015 (BBC News 2010).

Implicit in these developments is the concept that in the digital age no one should get left behind. Despite this, many people are at risk of being left behind in Australia. A significant number of disadvantaged people struggle to have or access the skills, tools or resources needed to digitally engage (Kearney 2009). Some commentators are predicting that even as the digital divide narrows, for many the 'divide' is getting deeper (Ewing 2013) and unless 
this is challenged with targeted interventions "digital exclusion ...may become the major social justice challenge of our time" (Perlgut 2011: 9).

According to a recent report by the Australian Council of Social Services (ACOSS) there are almost 2.3 million people living in relative poverty in Australia (ACOSS 2012). Whilst the digitally excluded in Australia are not a homogenous group, there is a strong correlation between socio-economic disadvantage and those digitally excluded sections of society who find it hard to afford or access the benefits of information communication technology (Vinson 2007). As a consequence those cohorts of society that are digitally excluded are more likely to encounter disadvantages in terms of strengthening their job skills, getting employment, benefiting from a quality education, obtaining critical information, socially connecting or accessing many health, educational and financial services that are essential to living in modern day Australia (Regional Telecommunications Review 2012).

Ironically, those that can potentially benefit most from the equalising opportunities of online services are those who have greater risk of being left behind (Comcast 2012).

\section{Overcoming the 'Divide' - no longer binary}

Digital inclusion is becoming a reasonably common term used to describe a range of topics, more often than not, concerned with equality of access to information communications technology (ICT) and the associated benefits (Searle 2009). Digital inclusion can be defined as providing access to high-speed broadband, ensuring affordability and ensuring that users can overcome adoption barriers and are empowered to have the skills to fully benefit from being digitally engaged.

Historically, digital inclusion has been shaped and defined by its more broadly known predecessor the 'digital divide'. This term has been around since the mid-1990s (Foster and Burkowski 2007) and has become so colloquial that it is difficult to determine a definitive meaning although initially it referred to those with and without Internet access. Some have contended that the digital divide has distinct and different levels depending on context. For example, for some it implies three levels of divide: global, social, and democratic (Norris 2001; Pluss 2003), while for most the 'divide' is simply dividing technological the 'haves' and 'have-nots' (Lloyd et al 2000).

In both cases, the terminology of a divide is aimed at conceptualising inequalities within society. A social divide generally refers to the gap between those with information and those without it (the haves and have-nots); whereas, a democratic divide, is generally used to signify those who do and do not 'engage, mobilise and participate in public life' using ICT (Norris 2001: 13). In other words, recognising that there is a distinction between voluntary and involuntary exclusion. 
Whilst the term 'a digital divide' is still widely used, digital inclusion definitions are more varied and tend to feature an expectation that only when all individuals have the ability to utilise the benefits ICT provides will we have a digitally inclusive society (Seale 2009: 11).

Generally, definitions of digital inclusion feature similar core elements based around what it means to be included. In essence this has been an attempt to address the issues of access, use, empowerment and participation (Seale 2009: 11). Despite the importance of aspects such as empowerment and participation in understanding digital inclusion, measurement tends to see access to and use of the Internet as the key determinant of whether someone is digitally included or not (Price Waterhouse Coopers 2009). Digital inclusion is emerging as a mainstream issue by default, simply because of the implications of being excluded: increasingly, exclusion negatively impacts an individual's health and wellbeing, their ability to learn and to enhance wealth, and their opportunities for civic and social engagement....

ICT now lies at the heart of most of the activities which are seen to constitute 'social inclusion' - from playing an active role in one's neighbourhood and community to maintaining one's personal finances. The inclusive role of ICT has recently been reinforced by the digital migration of most government and public services. Technologies such as the Internet, digital TV and mobile telephony are now important means of accessing and interacting with local government, health and welfare services, the criminal justice system and other areas of government. In all these instances, ICT use is implicated increasingly in what it means to be socially, economically, culturally and politically involved in 21st century society. (Selwyn and Facer 2007)

\section{Digital Inclusion Benefits - a false economy not to invest?}

In Australia, whilst there has been some research into the economic gains of getting more Australian households online (DBCDE 2010), there has not been a comprehensive overview drilling down into the factors that will influence how individuals and households can overcome the barriers to digital inclusion.

In the UK, EU and US the investigation into and debate around the social and economic benefits of inclusion have been more comprehensive than in Australia. Partially this can be attributed to the greater traction that the concept of inclusion has in these countries, especially in a policy context; and partially to the fact that the Howard government had never used the concept of social exclusion/inclusion in key policy frameworks (Notley 2008: 1011). Indeed, in addition to understanding the gains, research has sought to demonstrate the significant costs to society of not addressing exclusion. In most cases and especially in the UK experience it is demonstrated that over time the costs of digital exclusion are likely to increase and the social and economic gains of the digitally included populations magnify the 
cost to society of those excluded and potentially entrenched in disadvantage (Low Incomes Tax Reform Group 2012).

Digital inclusion and high speed broadband access is a means of furthering many national objectives, yet too often 'digital' is seen in the context of infrastructure, hardware and software. The real value, however, is in how digitisation can transform our economic, social and civic worlds, our public and private sector business models, and the life chances of individuals. A recent UK report by Booz and Co (in partnership with Go ON UK) summarised that universal digitisation has the potential to unlock substantial economic and social benefits for individuals, the business community, not for profit organisations and government. (Koss 2013)

The following table summarises the potential benefits of digital inclusion based largely on the work undertaken in the UK by Booz and $\mathrm{Co}$ and $\mathrm{PwC}$ and identifies the benefits in relation to individuals and sectors that have critical influence on digital inclusion.

Table 1. Potential benefits of digital inclusion

\begin{tabular}{|c|c|c|c|}
\hline Individuals & Business & Not for Profits & Government \\
\hline $\begin{array}{l}\text { Improved quality of } \\
\text { life through time } \\
\text { saving activities, } \\
\text { better information } \\
\text { and access. } \\
\text { Education: Improved } \\
\text { education outcomes } \\
\text { through opportunities } \\
\text { for inclusive learning } \\
\text { and developing social } \\
\text { capital. } \\
\text { Improved health and } \\
\text { wellbeing: Improved } \\
\text { access to health and } \\
\text { wellbeing information } \\
\text { and services (including } \\
\text { remote treatment) } \\
\text { and more support for } \\
\text { independent living } \\
\text { including tele-health } \\
\text { Employment } \\
\text { participation: } \\
\text { Improved (and } \\
\text { protected) } \\
\text { employability through } \\
\text { flexible working, } \\
\text { better ICT skills } \\
\text { aligned with market } \\
\text { needs and more } \\
\text { effective online job }\end{array}$ & $\begin{array}{l}\text { Economic growth } \\
\text { through. } \\
\text { Efficiency Savings: } \\
\text { Streamlining the cost } \\
\text { base and improving } \\
\text { efficiencies through } \\
\text { greater back office } \\
\text { automation and } \\
\text { greater use of online } \\
\text { information and } \\
\text { transactional services } \\
\text { (cloud technologies) }\end{array}$ & $\begin{array}{l}\text { Efficiency Savings. } \\
\text { Streamlining the cost } \\
\text { base and improving } \\
\text { efficiencies through } \\
\text { greater back office } \\
\text { automation and } \\
\text { greater use of online } \\
\text { information and } \\
\text { transactional services } \\
\text { (cloud technologies) } \\
\text { Improved Fundraising: } \\
\text { use of social media } \\
\text { providing new ways to } \\
\text { connect and mobilise } \\
\text { support } \\
\text { More effective } \\
\text { communication with } \\
\text { target supporters and } \\
\text { donors }\end{array}$ & $\begin{array}{l}\text { Service transformation. } \\
\text { Public Sector efficiencies } \\
\text { through } \\
\text { - } \quad \text { Lower transaction } \\
\text { costs } \\
\text { - } \quad \text { FTE savings } \\
\text { - } \quad \text { Reduced duplication } \\
\text { / multiple } \\
\text { submissions } \\
\text { Potential increase in } \\
\text { tax revenue and } \\
\text { reduction in benefit } \\
\text { payments } \\
\text { Faster response } \\
\text { times } \\
\text { Improved choice } \\
\text { and convenience. } \\
\text { Democratic } \\
\text { engagement }\end{array}$ \\
\hline
\end{tabular}




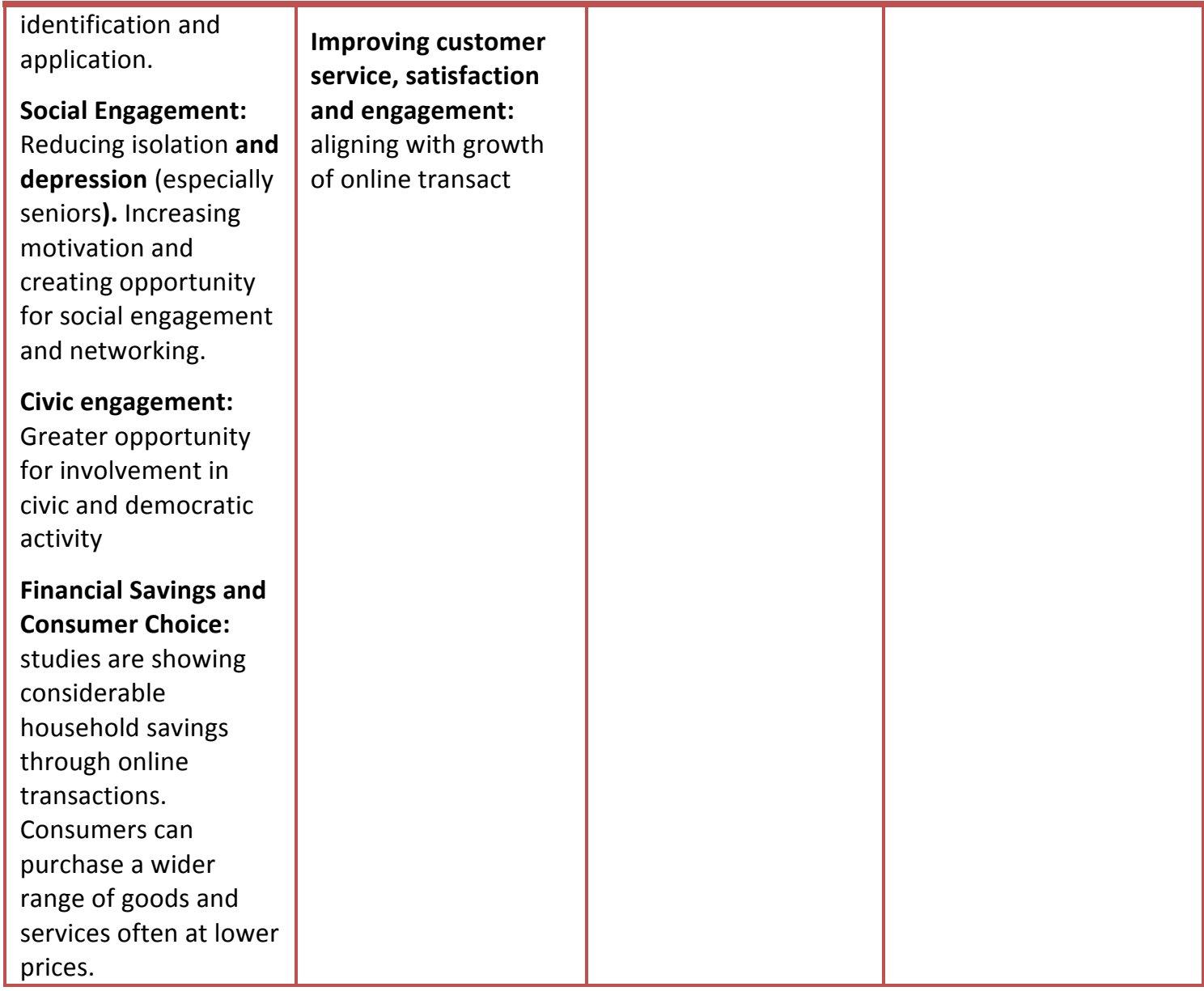

In late 2009 the UK Champion for Digital Inclusion, Baroness Martha Lane Fox, commissioned PricewaterhouseCoopers LLP (PwC) to report on the potential scale of the 'digital dividend' to Britain of achieving greater digital inclusion. Key findings included the following:

- Digitally excluded low-income households were missing out on $£$ 1billion a year from shopping and paying bills online;

- Home access to a computer was shown to improve educational achievement and boost lifetime earnings;

- Unemployed people who get online substantially increased their chances of getting a job;

- If all digitally excluded adults got online and made just one transaction a month online, instead of offline, government could save around £9oom per annum.

- The total potential economic benefit from getting everyone in the UK online was estimated to be in excess of £22billion (Price Waterhouse Coopers 2009: 2).

Whilst a similarly detailed analysis is yet to be carried out in Australia, there is a growing body of evidence demonstrating a compelling economic case for ensuring all Australians are digitally included. In 2002 the Australian social enterprise, Infoxchange, launched a large 
digital inclusion pilot project across two high-rise, public housing estates in inner Melbourne. These projects have been independently evaluated and have demonstrated considerable social and economic benefits (Kearney 2009; Meredyth 2006)

'This project has delivered a number of very important milestones in a community that has long term and intergenerational social and economic challenges. Removing the digital divide in this community is one critical component in the process of changing the long term social disadvantage experienced by residents on the Collingwood estate.' (Isoquant 2010: 65)

The Global Consulting firm A.T. Kearney provided an in-depth analysis of the economic return on investment of the initiative. This research demonstrated that boosting social inclusion through enhanced digital connectivity is an effective way to improve outcomes in terms of the costs of service provision for health and countering anti-social behaviour. As well, the efficient access to information reduces costs to the public health system and empowers patients when making health and wellbeing choices. For those digitally connected A.T.Kearney were able to quantify over $\$ 5.9$ million of economic benefits (Kearney 2009) across four interrelated areas:

- Education and Employment benefits;

- Communication and Connectivity benefits;

- Transactional efficiencies; and,

- Health and Wellbeing benefits.

In late 2010 the Australian Department of Broadband, Communications and Digital Economy commissioned a report by The Allen Consulting Group to quantify the economic gains of getting more Australian households online (Allen Consulting Group DBCDE 2010). Entitled "Quantifying the Possible Economic Gains of Getting More Australian Households Online", this report estimated that if the number of Australian households connected to broadband Internet increased by $10 \%$ this would provide $\$ 2.4$ billion a year in household gains (in current prices) largely through time-saving activities such as telecommuting, distance study, online savings and access to health services; if there was a $20 \%$ increase in connection to household broadband services then gains would amount to $\$ 4$.8billion. The report estimated that the value of time an average Australian household will spend on the Internet amounts to approximately \$7,699 per year (Allen Consulting DBCDE 2010: 39).

Critically, the realisation of any social or economic benefit requires overcoming the barriers causing many people in Australia to be digitally excluded. The following sections discuss who in Australia is excluded and why. 


\section{Measuring Digital Inclusion: How does Australia Fare?}

The levels of digital exclusion in Australia have declined in recent years, although a significant proportion of the population remains excluded. In 2013, Internet diffusion rates have crept up but the distribution of access is far from equitable. The recent Social Inclusion Board report, How Australia is Faring, indicated that $79 \%$ of homes now have Internet access (95\% in the highest income quintile and just $55 \%$ in the lowest) (Australian Government. 2012b, Cole 2012). Critically, 27\% of all households (2.3 million households) are not using broadband and 1.796 million households (21\%) have no Internet connection at all (ABS December 2012).

Many groups within Australia are significantly more likely to be excluded than others:

- Culturally and linguistically diverse communities

- Refugees and asylum seekers

- People with a disability

- Low income households

- Sole-parent families

- Seniors

- The unemployed or under-employed

- Indigenous communities

- People in remote communities

In Australia if you are disabled, in a low-income household or dependent on a parenting payment, an age pension, disability support pension or a Newstart allowance, then the likelihood of having no Internet at home is twice to almost five times higher than the national average (ABS December 2012). In 2011, only 57\% of people over 65 years of age used the Internet, although this was up from just over 40\% in 2009 (Morsillo 2012) and single parent households with dependent children under 15 lagged comparable dual parent households by 15 - 16\% for Internet and broadband access (Cole 2012).

Indigenous households in Central Australia are $76 \%$ less likely to have Internet access than non-indigenous metropolitan households (Crouch et al 2011). Professor Lester-Irabinna Rigney, Dean of Aboriginal Education at Adelaide University argues if nothing is done to close the digital gap between Indigenous and non-Indigenous Australians, there we will see an emergence of 'digital ghettos' (Rigney 2011: 8).

Exclusion is also concentrated in areas of socio-economic disadvantage such as urban fringe areas, public housing estates and for those with no fixed abode (Kearney 2009). There is also a significant $8 \%$ difference between urban and rural use (Cole 2012). 


\section{Digital Inclusion - the whole greater than the sum of parts}

When the digital divide or state of digital inclusion is discussed in Australia, it is often in a broad non-specific context with sometimes a singular focus on a particular aspect of digital inclusion such as affordability or accessibility. For example, much of the discussion to date around the potential of the National Broadband Network (NBN), including Australian government NBN public policy, focuses predominantly on geographical location and physical service delivery (Lee 2011), and largely ignores other barriers to usage (Ellis 2012; Nansen 2012). Of course, there is no debating that individual components of digital inclusion, such as the infrastructure itself, are critically important but if only these or individual aspects are continually addressed in isolation their impact will be limited.

We would see that core to digital inclusion is ensuring:

- Awareness - that all members of a community should understand the benefits of information communication technology from basic to advanced level.

- Affordable and Available - All members should have affordable access Internet connected hardware devices and high speed broadband plans

- Accessible - All members, regardless of their background, income, ability or location, should not be prevented from taking advantage of the economic, educational, social benefits and opportunities available through ICT (Building Digital Communities 2012).

Importantly, the core components of digital inclusion complement each other and should not be considered in isolation from each other, as so often they are. When digital inclusion has been tackled more holistically the economic and social benefits to individuals and societies have been considerable, as discussed earlier, and a number of trends in society suggest that this pattern is likely to continue, if not amplify.

\section{Adoption and Digital Literacy}

Digitally excluded people do not engage with digital technology due to a variety of reasons. Involuntary barriers can be related to unaffordability, a lack of requisite digital skills, or a lack of formal or peer support (ACMA 2009). Voluntary reluctance to engage is often linked to low motivation due to fear or perceived lack of relevance. In 2012, the Australian arm of the World Internet Project found that $51 \%$ of people who do not have the Internet identify as having no interest or do not find it useful (Ewing 2013). However, in a 2009 study, ACMA found that most adults claiming no interest to engage with new communication technologies are not making an active choice to be excluded and for some reluctance was simply a cover for personal skill shortages (ACMA 2009: 47). 
Digital inclusion therefore also requires raising awareness of the potential benefits of being digitally included (Price Waterhouse Coopers 2009) and promoting relevant content and services. If relevant content and services are not easily identified then interest can wane. This is critically important in culturally and linguistically diverse communities, for example, in communities where relevant content in a preferred, spoken or mother-tongue language is critical for meaningful Internet use.

\section{Digital Literacy}

\section{Digital literacy “is about mastering ideas, not key strokes” (Gilster 1997)}

At its core, digital literacy is about having a competency around the use of digital tools. Being digitally literate is not just understanding digital technology, but using digital technology to achieve everyday tasks and goals (Martin 2009), be that communicating on Skype, accessing relevant content or processing online banking. Digital literacy is not a static skill; it is part of a commitment to an ongoing process of understanding how technology can be used to achieve educational, economic and social goals.

\section{Affordability}

Whilst the digitally excluded are clearly not a homogenous group, for many excluded people affordability is often a primary obstacle and overcoming other barriers cannot be achieved without a deliberate intervention to ensure genuine affordability. Whilst the price of an Internet connected device has been dropping in recent years, affordability of hardware and Internet connectivity needs to be viewed in the context of an individual's own limited and fixed income (Isoquant 2010; Kearney 2009) especially where the digitally excluded are compounded by multiple dimensions of disadvantage (Vinson 2007).

There is currently uncertainty whether the entry level cost for an NBN service may be too high to accommodate many Australian households (Morsillo 2013), especially low income households and those under financial stress. In addition, more could be done to ensure all forms of broadband pricing structures and information is accessible and understandable in a way that helps individuals make meaningful comparisons.

\section{Consumer/User Education and Protection}

Digital Inclusion also requires cyber safety, education and protection. It requires ensuring people can, based on unbiased advice and information, make informed decisions about navigating the digital world, purchasing and maintain equipment and services, and understanding their rights. This type of information is often not included in digital literacy training, which frequently focuses on skills rather than knowledge, but is critical in terms of 
ensuring that as people and consumers engage ever more deeply they know how to safeguard personal information, can protect children from inappropriate content or cyber bullying, can ensure they reduce the risk of computer viruses (Building Digital Communities 2012: 8). In addition, more could be done to ensure pricing structures and information about technology hardware and connection plans are accessible and understandable in a way that helps individuals make meaningful comparisons.

\section{Accessibility}

A core component of digital inclusion is also accessibility - public accessibility (as a start) in safe and secure facilities, such as digital hubs or community centres, but also broader accessibility so that all people regardless of income, background, ability or location, can engage both economically and socially in the digital age. This is especially important for people with a disability where inaccessible websites or content (especially for the visually impaired or those with cognitive or motor control impairments) limit engagement (Building Digital Communities 2012: 56). And whilst Disability Care (NDIS) will assist many disabled people, all organisations should be increasingly cognisant of meeting accessibility standards.

\section{A framework for Digital Equality - avoiding another divide}

The digital divide, as a concept, has certainly helped focus attention on how the spread of information, communication technology can either foster greater equality or reinforce social and economic stratification. In many ways the digital divide has become a mainstream issue in economic and social development (Wynne 2007), yet our understanding of inclusion is inhibited if we do not evolve our understanding in line with the complex ever-evolving relationship between technology and our social structures. It is no longer a question of being connected or disconnected (Nansen et al 2012); it is increasingly about the levels of digital engagement and the ability to more fully participate in society (Warschauer 2004; Black 2007; Notley 2008).

The speed of technology change means that advancing digital participation involves addressing a moving target. Most recently, mobile devices, social media and cloud technology, for example, are changing the way people engage with the world. There are a number of significant trends impacting not just the concept of digital inclusion today, but more importantly how it needs to be addressed in future years to avoid an emerging digital participation gap.

We would argue that the factors which are likely to have an impact on digital inclusion include:

- Technology change - convergence of technologies (phone, tablet, PC) and introduction of new forms of engagement (interactive, Internet enabled television) 
and a high speed broadband network, if affordable and accessible, will change the flavour of inclusion projects.

- Demographics - net immigration, especially refugees and asylum seekers will possibly require ongoing digital inclusion support;

- Market forces - Price reductions also present opportunities for greater digital inclusion approaches;

- Shift to online service provision across all sectors increases urgency of digital inclusion and presents challenges around ensuring equitable access.

\section{Dimensions of Digital Equality}

In 2013 Infoxchange sought to not only understand the core foundations of digital inclusion but to connect those elements to the required social outcomes. This framework developed by the Infoxchange allows those working to develop digitally included citizens a means of taking a holistic approach to that work. The following diagram (Figure 1) provides both a high level view of digital inclusion and acts as a framework and planning tool for both policy and programme development.

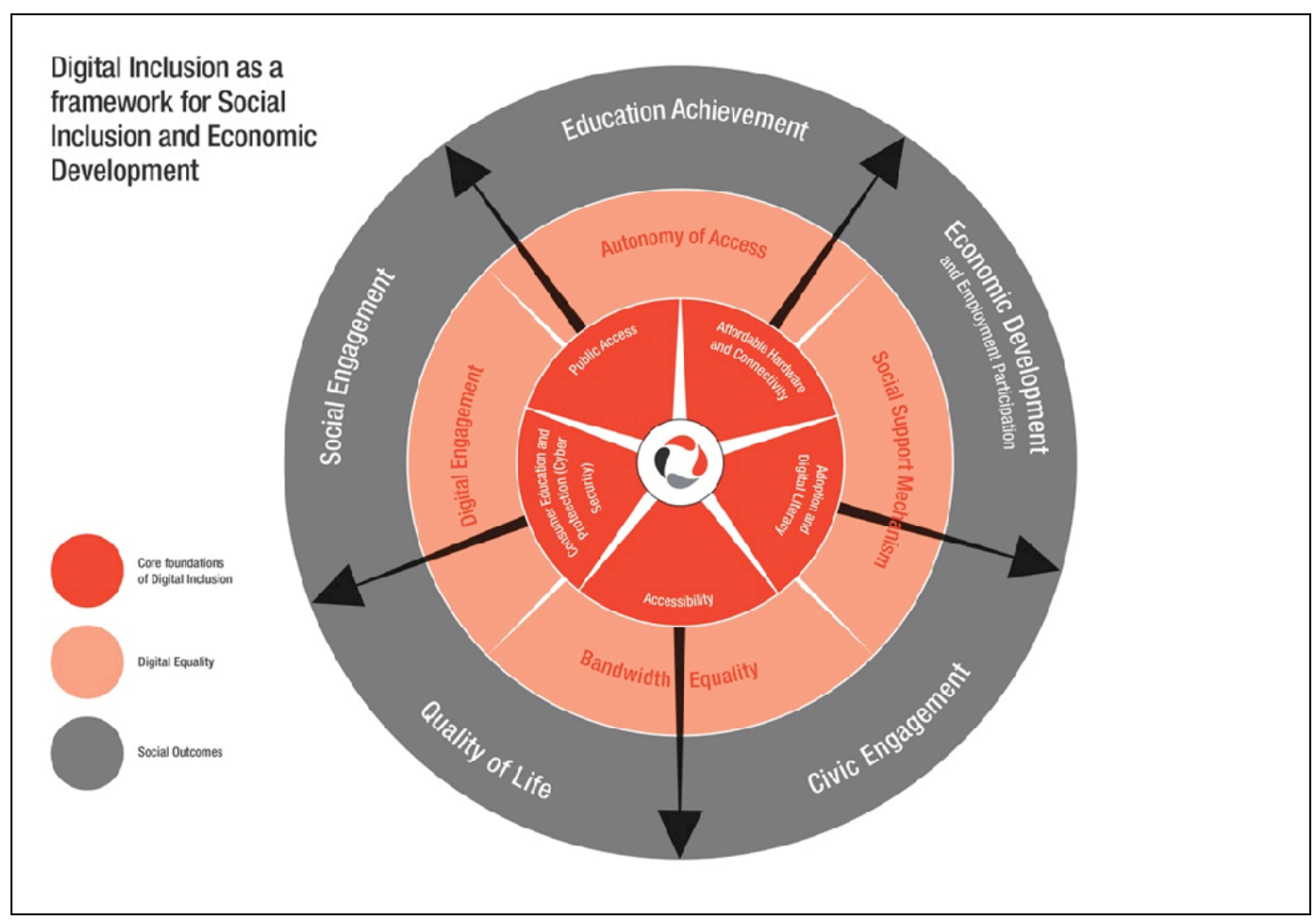

Figure 1. Digital Inclusion as a framework

So getting those currently excluded connected is of paramount importance, but the overall challenge is expanding the effective utilisation of technology so that its benefits are more equitably distributed throughout Australia (Freshlands 2007). In this regard, once people 
are connected there is a range of ongoing requirements to ensure that we do not see the emergence of a participation gap, as captured in the above diagram. These include:

Bandwidth Equality - Overcoming the inequality of bandwidth is becoming increasingly important so that everyone has the technical means to benefit from online services as they develop (DiMaggio 2001). This implies a certain minimum download speed and sufficient, affordable data allowance to ensure that citizens are not excluded from services due to technical limitations or affordability. The NBN, if genuinely affordable, will go a long way in this regard.

Autonomy of Access (including extending home access) - Digital equality is about ensuring greater autonomy of access and the freedom an individual has to choose how s/he engages with the Internet, when and where. This includes understanding whether users log on from work, from digital hubs or from their own home, whether their access is monitored or unmonitored, during limited hours or at will (DiMaggio 2001). Not having autonomy of access can disadvantage people in all manner of ways, including:

- The ability to apply for jobs or take on telework opportunities, (especially important for the disabled, carers and those in remote locations).

- The ability of patients to find health information or securely access e-health services (including online consultations)

- The ability of students to learn outside of formal learning environments or outside of business hours.

- The ability of citizens to access government services that are increasingly only online.

Deepening Digital Engagement - continuing the development of user skills and capability, aligned with changing technology. Digital equality implies ongoing learning; not assuming that the problem is 'fixed' with a connection and basic literacy. As the number of online activities a person engages with increases, so does the likelihood of needing more intermediate and advanced skills. Online activities that would have once seemed advanced, such as online banking, are increasingly being seen as basic and many are more associated with home based access rather than through community access points. In many ways the goal posts are moving; the basic level of digital engagement is much higher than it was a short time ago (Helsper 2008). With the roll out of a high speed broadband network this division between basic, intermediate and advanced users may widen preventing some in society from capitalising on the potential of a high speed broadband network ( 2008). 
Social Support Mechanisms - facilitating and maintaining social support mechanisms is critically important so that users have access to advice from more experienced users (ideally trusted peers) on an ongoing basis, especially as technology continues to change on a frequent basis. There are numerous good examples of social support mechanisms at a national scale, such as Go On UK, Connect 2 Compete (USA) and Digital Unite and Spring Online (UK).

\section{Achieving Digital Equality}

The scale of the challenge around digital inclusion is a large one and responding to this challenge requires a significant social shift for Australia. There are many good examples of small digital inclusion activities, but to conquer the digital divide and work towards digital equality, coordination is required to enable replication and aggregation at a greater scale.

In order to develop these responses both at a programme level but more importantly at a policy level a key part of that shift will be for governments, corporates and the community sector to better understand what the root and the linked causes of digital exclusion are.

The framework presented in this paper goes some way to presenting a holistic view of digital inclusion which will allow for those policy and programme solutions to be developed and implemented to effect. For Infoxchange this framework provides a template to ensure that all digital inclusion projects no matter how specific in scope or small in size can be designed with the desired social outcomes and the related digital inclusion factors in clear view.

We would argue that the work needs to be progressed on a national and cohesive scale to address the issue of digital exclusion. This would include the requirement for an agreed national plan with clear, measurable targets to get Australians online and demonstrably engaged by 2020 - a 2020 Vision. Achieving ambitious goals around digital equality will not occur (and the digital participation gap will widen) if a more targeted and holistic approach is not undertaken and this requires consideration of more innovative public and private sector partnerships that can improve both scale and impact. This requires leadership and much greater coordination perhaps under a government organisation such as Australian Communications and Media Authority (Perlgut 2011). 


\section{References}

ACOSS. 2012. Poverty in Australia: ACOSS Paper 194. Strawberry Hills, NSW: Australian Council of Social Services, 2012. Available from: http://www.acoss.org.au/uploads/ACOSS\%20Poverty\%20Report\%202012_Final.pdf.

Allen Consulting Group. 2010. "Quantifying the Possible Economic Gains of Getting More Australian Households Online". Report by the Allen Consulting Group Pty Ltd for the Department of Broadband, Communications and the Digital Economy, November 2010. http://pandora.nla.gov.au/tep/128312

Australian Government. 2012a. Regional Telecommunications Review 2011-12 - Regional Communications: Empowering Digital Communities. Review of Government Policy. Regional Telecommunications Independent Review Committee, December 2011. Available from: http://www.rtirc.gov.au/files/2012/06/Regional_CommunicationsEmpowering_digital_communities.pdf.

Australian Government. 2012b. "Social Inclusion in Australia - How Australia is faring". 2nd Edition, Australian Social Inclusion Board, Australian Government, 2012, Available from: http://www.socialinclusion.gov.au/sites/www.socialinclusion.gov.au/files/publications/p df/HAIF_report_final.pdf.

Australian Bureau of Statistics. 2012. Internet Activity June 2012. 8153.0 Australian Bureau of Statistics, Australia, December 2012. Available from: http://www.abs.gov.au/ausstats/abs@.nsf/mf/8153.0

Kearney, A.T. 2009. Assessing the Economic Benefits of Digital Inclusion, 2009. Available from:

http://www.digitalinclusion.net.au/sites/www.digitalinclusion.net.au/files/Assessing\%2 othe\%20economic\%2obenefits\%20of\%20digital\%20inclusion_o.pdf.

ACMA. 2009. Adult Digital Media Literacy: Qualitative Research Report. Australian Communications and Media Authority (ACMA), August 2009. Available from: http://www.acma.gov.au/webwr/_assets/main/lib310665/adult_digital_media_literacy _needs_research.pdf. The Case for Universal Digitisation, Booz \& Co, 2013

Black, Rosemary; Atkinson, John. 2007. ACT Government quoted in 'Addressing the Digital Divide in Rural Australia'. First presented at AusWeb 07, The 13th Australasian World Wide Web conference Available from: http://ausweb.scu.edu.au/awo7/papers/refereed/black/paper.html

Cole, Jeffrey et al. 2012. World Internet Project (Fourth Edition). World Internet Project, University of Southern California, 2012.

Comcast. 2012. Conquering the Digital Divide; Closing the Broadband Opportunity Gap. Internet Essentials from Comcast, January 2012. Available from: http://www.Internetessentials.com/sites/Internetessentials.com/files/reports/launchrep ort.pdf.

Chartered Institute of Taxation . 2012. "Digital Exclusion: A Research Report" by the Low Incomes Tax Reform Group of The Chartered Institute of Taxation. Low Incomes Tax Reform Group, April 2012. Available from:

http://www.litrg.org.uk/Resources/LITRG/Documents/2012/o5/digital_exclusion__litrg_report.pdf.

Crouch , Rennie. E. et al. 2011. "Home Internet for Remote Indigenous Communities". Australian Communications Consumer Action Network, Sydney 2011. Available from: http://www.cci.edu.au/sites/default/files/mcummins/Home\%2oInternet\%20for\%2orem ote\%2oIndigenous\%20communities.pdf. 
DiMaggio, Paul; Hargittai, Eszter. 2001. From the 'digital divide' to 'digital inequality': Studying Internet Use As Penetration Increases. Working Paper \# 5, Summer, 2001. Available from: http://www.princeton.edu/ artspol/workpap15.html

Ellis, Katie. 2012. 'It means inclusion: a creative approach to disability and telecommunications policy in Australia". Telecommunications Journal of Australia. 61 (2): pp. 25.1 to 25.8. 2012. Available from: http://dx.doi.org/10.779o/tja.v62i2.293

Ewing, Scott. 2013 . “The Digital Divide: Narrowing but Deepening.” Swinburne University, April 2013.

Foster, S; Burkowsi, A. 2007. Quoted in 'Addressing the Digital Divide in Rural Australia', Black, Rosemary and Atkinson, John. 2007. First presented at AusWeb 07, The 13th Australasian World Wide Web conference Available from: http://ausweb.scu.edu.au/awo7/papers/refereed/black/paper.html

Freshlands. 2007. "Digital Inclusion: A discussion of the Evidence Base". Prepared for UK Online Centres, July 2007, 35-40

Gilster, Paul. 1997. Digital Literacy. Wiley Computer Publishing, New York, 1997.

Helsper, Ellen. 2008. "Digital inclusion: an analysis of social disadvantage and the information society". Department for Communities and Local Government, London, UK, p.11. Available from: http://eprints.lse.ac.uk/26938/

BBC News. 2010. "Internet Access Is 'a Fundamental Right'." BBC News, March 8, 2010. Available from: http://news.bbc.co.uk/2/hi/8548190.stm.

Institute of Museum and Library Services. 2012. Building Digital Communities: A framework for action. Washington, DC: Institute of Museum and Library Services, University of Washington, International City/ County Management Association January 2012. 1

Isoquant Research. 2010. WiredCommunity@Collingwood: Final Evaluation Report. Melbourne: Isoquant Research, June, 2010.

Koss, Victor et al. 2013. "This is for Everyone”: The Case for Universal Digitisation, Booz \& Co, 2013.

Lee, David. 2011. 'The digital divide: the Australian Government's role in addressing 'ability". Telecommunications Journal of Australia. 61 (2): pp. 25.1 to 25.8. Available from: http://dx.doi.org/10.7790/tja.v61i2.211.

Lloyd, Rachel; Harding, Ann; Hellwig, Otto. 2000. "Regional Divide?: a Study of Incomes in Regional Australia.” Australasian Journal of Regional Studies. 6, no. 3 (2000): 271-292.

Martin, Allan. 2009. "Digital Literacy for the Third Age: Sustaining Identity in an Uncertain World" .eLearning Papers, $\mathrm{N}^{\circ}$ 12, February 2009. Available from: http://www.elearningeuropa.info/files/media/media18500.pdf .

Meredyth, Denise et al. 2006. "Wired High Rise: a community-based computer network: final report". Swinburne University of Technology. Faculty of Life and Social Sciences. Institute for Social Research, Swinburne University of Technology, 2006. oai:vtl.cc.swin.edu.au:swin:6271.

Morsillo, Robert. 2012. 'Affordable broadband for all Australians'. Telecommunications Journal of Australia. 62 (5): pp. 80.1 to 80.16. Available from: http://dx.doi.org/10.7790/tja.v62i5.363.

Morsillo, Robert. 2013. 'LIMAC Affordability Research 2002-12' presented to ACCAN Affordability Forum, March 2013.

Nansen, Bjorn, et al. 2012. 'Digital Literacies and the National Broadband Network: Competency, Legibility, Context'. Media International Australia 145 (November 2012): $64-74$. 
Norris, Pippa. 2001. Digital Divide: Civic Engagement, Information Poverty and the Internet Worldwide. Cambridge University Press, 2001

Notley, Tanya M; Foth, Marcus. 2008. "Extending Australia's digital divide policy: an examination of the value of social inclusion and social capital policy frameworks". Australian Social Policy 7, Australian Government Department of Families, Housing, Community Services and Indigenous Affairs. July 2008. Available from: http://apo.org.au/research/extending-australias-digital-divide-policy-examinationvalue-social-inclusion-and-social-o

Perlgut, Don. 2011. "Digital Inclusion in the Broadband World: Challenges for Australia." presented at the Communications Policy and Research Forum, Sydney, November 2011.

Pluss, M. 2003. "Geographical Dimensions of the Digital Divide - ICT Update." Geography Bulletin 35, no. 4 (Spring 2003): 157-159.

Price Waterhouse Coopers. 2009. Champion for Digital Inclusion - the case for digital inclusion, 2009

Rigney, Lester-Irabinna. 2011. 'Indigenous education: Creating classrooms of tomorrow today' paper, first presented at Indigenous Education: Pathways to success, August 2011, 8.

Seale, Jane. 2009. Digital Inclusion. Research Briefing. Teaching and Learning Research Programme, University of Southampton, December 2009. Available from: http://www.tlrp.org/docs/DigitalInclusion.pdf.

Selwyn, Neil; Facer, Keri. 2007. "Beyond the Digital Divide: Rethinking Digital Inclusion for the 21st Century". Futurelab, 2007. Available from:

http://archive.futurelab.org.uk/resources/documents/opening_education/Digital_Divid e.pdf.

Sparks, Ian. 2009. "Internet Access Is a Fundamental Human Right, Rules French Court." Mail Online, June 12, 2009. Available from: http://www.dailymail.co.uk/news/article1192359/Internet-access-fundamental-human-right-rules-French-court.html.

Vinson, T. 2007. "Dropping off the edge: The distribution of disadvantage in Australia". Jesuit Social Services and Catholic Social Services Australia, 2007.

Walton, Peter. 2013. "Digital Equality and Social Inclusion". Paper presented to ACCAN Affordability Forum, March 2013

Warschauer, Mark. 2004. "Of Digital Divides and Social Multipliers: Combining Language and Technology for Human Development". University of California, Irvine, 2004. Available from: http://www.gse.uci.edu/person/warschauer_m/docs/multipliers_1.pdf

Wynne, Maria; Cooper, Lane. 2007. "Digital Inclusion Imperatives Offer Municipalities New Social and Economic Opportunities". Power Up - The Campaign for Digital Inclusion, Microsoft, 2007, 4 .

Cite this article as: Walton, Peter; Kop, Tegan; Spriggs, David; Fitzgerald, Brendan. 2013. 'Digital inclusion. Empowering all Australians'. Australian Journal of Telecommunications and the Digital Economy 1 (1): pp.9.1 - 9.17. DOI: 10.7790/ajtde.v1n1.9

Available at: http://telsoc.org/journal 